\title{
The impact of dynamic factors on surgical outcomes after double-door laminoplasty for ossification of the posterior longitudinal ligament of the cervical spine
}

\author{
Clinical article
}

\author{
Keishi Maruo, M.D., ${ }^{1}$ Tokuhide Moriyama, M.D., ${ }^{1}$ Toshiya Tachibana, M.D., ${ }^{1}$ \\ Shinichi Inoue, M.D., ${ }^{1}$ Fumihiro Arizumi, M.D., ${ }^{1}$ Takashi Daimon, Ph.D., ${ }^{2}$ \\ AND Shinichi Yoshiya, M.D. 1 \\ Departments of ${ }^{1}$ Orthopaedic Surgery and ${ }^{2}$ Biostatistics, Hyogo College of Medicine, Hyogo, Japan
}

\begin{abstract}
Object. Laminoplasty is the preferred operation for most patients with cervical myelopathy due to multilevel ossification of the posterior longitudinal ligament (OPLL). Recent studies have demonstrated several significant risk factors for poor clinical outcomes after laminoplasty, including older age, lower preoperative Japanese Orthopaedic Association (JOA) score, postoperative change in cervical alignment, cervical kyphosis, and high occupying ratio of the OPLL (that is, the ratio of the greatest anteroposterior thickness of the OPLL to the anteroposterior diameter of the spinal canal at the same level on a lateral image). However, the impact of dynamic factors on clinical outcomes is unclear. The purpose of this study is to assess the impact of dynamic factors on the clinical outcome after laminoplasty for cervical myelopathy due to OPLL.

Methods. A consecutive series of patients who underwent laminoplasty for cervical myelopathy due to OPLL between 2003 and 2009 was retrospectively reviewed. The indication for laminoplasty at the authors' hospital included preoperative straight or lordotic alignment of the cervical spine and an occupying ratio of OPLL less than $60 \%$. The JOA score and recovery rate were used to evaluate clinical outcomes. A poor clinical outcome was defined as a recovery rate of less than $50 \%$. Patient factors examined along with outcome included age, preoperative JOA score, preoperative somatosensory evoked potentials, preoperative motor evoked potentials, body mass index, and presence of high intensity on MRI. Radiographic measures included the preoperative C2-7 lordotic angle, preoperative C2-7 range of motion (ROM), preoperative segmental ROM at the level of myelopathy, and the occupying ratio of OPLL.

Results. There were 45 patients ( 33 males and 12 females). The mean follow-up period was 4 years (range 2-6.8 years). The mean patient age was 66.9 years (range $50-85$ years). The mean JOA score significantly increased from 9.1 before surgery to 13.1 at the final follow-up. The mean recovery rate was $51.2 \%$. Nineteen patients $(42 \%)$ had a recovery rate of less than 50\%. Patient factors were not associated with surgical outcomes. Only the preoperative C2-7 ROM was significantly greater in the poor surgical outcome group $\left(23.1^{\circ} \mathrm{vs} 14.1^{\circ}\right)$. Receiver operating characteristic curve analysis showed that the optimal preoperative C2-7 ROM cutoff was $20^{\circ}$. Logistic regression analysis revealed that patients with a preoperative $\mathrm{C} 2-7 \mathrm{ROM}$ of greater than $20^{\circ}$ had a 4.6 times higher risk $(\mathrm{p}=0.021)$ of a poor clinical outcome, indicating that dynamic factors may have an impact on the surgical outcome of laminoplasty. cal spine.

Conclusions. Fusion surgery may be a useful strategy in patients with preoperative hypermobility of the cervi(http://thejns.org/doi/abs/10.3171/2014.8.SPINE131197)
\end{abstract}

\section{Key Words - ossification of the posterior longitudinal ligament $\quad$ - cervical spine laminoplasty - dynamic factors - surgical outcomes • C2-7 range of motion}

$\mathrm{O}$ SSIFICATION of the posterior longitudinal ligament (OPLL) is a common disease in Asian countries, and its prevalence has been reported to be $1.9 \%$ $4.3 \%$ in Japan. ${ }^{19}$ Cervical OPLL leads to myelopathy and has various causes, including genetic factors, minor trauma, static compression of the spinal cord, and dynamic factors. The disease typically occurs in men and generally

\footnotetext{
Abbreviations used in this paper: $\mathrm{BMI}=$ body mass index; $\mathrm{JOA}=$ Japanese Orthopaedic Association; MEP = motor evoked potential; OPLL $=$ ossification of the posterior longitudinal ligament; ROC $=$ receiver operating characteristic; $\mathrm{ROM}=$ range of motion; $\mathrm{SSEP}=$ somatosensory evoked potential.
}

in those older than 50 years. ${ }^{1,3,8,18,21}$ Patients with progressive myelopathy require surgical treatment. The treatment options for cervical OPLL include anterior decompression and fusion, posterior laminectomy or laminoplasty, and posterior laminectomy and fusion surgery. The anterior decompression and fusion technique can provide direct decompression to the spinal cord and stability of the cervical spine; however, this is technically demanding and may lead to a higher incidence of complications, such as nonunion, dislodgment of grafts, and dural tears., ${ }^{2,23}$ Since the 1970s in Japan, laminoplasty has been preferred as the safe and effective operation for most patients with cervical myelopathy caused by multilevel OPLL. ${ }^{5,22}$ The effects of 


\section{Surgical outcome after laminoplasty for cervical OPLL}

laminoplasty have been published in many reports; however, there are various factors associated with poor clinical outcome, such as duration of myelopathy, age at the time of surgery, preoperative severity of myelopathy, and presence of an MRI signal change..$^{6,15-17}$ Recent reports have indicated 2 major factors associated with poor clinical outcome after laminoplasty: 1) kyphotic alignment of the cervical spine and 2) size of the OPLL.7,12 Therefore, either anterior decompression and fusion or posterior laminectomy and fusion surgery were selected for patients with kyphotic alignment of the cervical spine or a large OPLL. However, some patients have had poor clinical outcomes after laminoplasty. Several studies have focused mainly on static factors, such as cervical alignment or the OPLL size, and little is known about the impact of dynamic factors on surgical outcomes. The purpose of this study was to assess the predictive factors associated with poor surgical outcomes, particularly the impact of dynamic factors, after laminoplasty for cervical OPLL.

\section{Methods}

\section{Patient Population}

This retrospective study comprised a consecutive series of patients treated with laminoplasty for the surgical management of cervical OPLL. After receiving institutional review board approval, we identified patients with OPLL from a single institutional database who underwent laminoplasty between 2003 and 2009 for cervical myelopathy. The minimum follow-up was 2 years. Laminoplasty was indicated for OPLL that extended more than 3 levels, an occupying ratio of OPLL (that is, the ratio of the greatest anteroposterior thickness of the OPLL to the anteroposterior diameter of the spinal canal at the same level on a lateral image) of less than $60 \%$, and lordotic alignment of the cervical spine. OPLL patients with traumatic cervical spinal cord injury who were surgically treated for symptomatic thoracic OPLL and who underwent instrumented fusion with an anterior or posterior approach were excluded from the study. Patient demographic data and surgical data were obtained from medical records and operative reports.

\section{Surgical Technique}

Our standard posterior surgical procedure is a double-door laminoplasty with preservation of posterior cervical elements. ${ }^{26}$ The laminae were expanded one above and one below the existing level of OPLL, typically at C3-7. A left-sided approach was normally used, and the paravertebral muscle was detached from each lamina between C-3 and C-7 while preserving the muscles attached to the $\mathrm{C}-2$ spinous process. An angled bone saw was used to cut the spinous processes from C-3 to C-6 at the base. The right-sided laminae were exposed while preserving posterior elements, including spinous processes and the supraspinous and interspinous ligaments. The laminae were split at the midline, and a high-speed drill was used to create bilateral gutters. After the bilateral laminae were elevated, hydroxyapatite spacers were inserted into the elevated lamina with nylon sutures.

\section{Clinical Assessment}

The Japanese Orthopaedic Association (JOA) score, recovery rate, and complications were reviewed to evaluate clinical outcomes. Hirabayashi's method was used to calculate the recovery rate of the JOA score..$^{9}$ Recent study-reported clinical results were divided into 4 groups as follows: $75 \%$ or higher (excellent), 50\%-74\% (good), $25 \%-49 \%$ (fair), and less than $25 \%$ (poor). ${ }^{25}$ Therefore, we defined a good clinical outcome as a recovery rate greater than $50 \%$ in this study. Patient factors of age, sex, preoperative JOA score, preoperative somatosensory evoked potentials (SSEPs), preoperative motor evoked potentials (MEPs), body mass index (BMI), and diabetes mellitus were assessed to determine any association with poor clinical outcomes. Radiographic measurements included the $\mathrm{C} 2-7$ lordotic angle, preoperative $\mathrm{C} 2-7$ range of motion (ROM), preoperative segmental ROM at the level of cervical myelopathy, change in $\mathrm{C} 2-7$ angle, occupying ratio of OPLL, and presence of a T2 high-intensity lesion on MRI. The C2-7 angle was measured between the posterior border of the $\mathrm{C}-2$ vertebral body and the posterior border of the C-7 vertebral body (Fig. 1). The Cobb method was used to measure the C2-7 ROM through the change in the maximal flexion and extension by lateral radiographic view. Determination of the level of myelopathy was comprehensively assessed by 1) clinical examinations and 2) blocked level observed on myelography and level of the T2 high-intensity lesion on MRI.

\section{Statistical Analysis}

Continuous variables are presented as means \pm SDs with ranges, and categorical variables are presented as frequencies and percentages. The independent Student t-test was used to compare continuous and categorical variables between the good recovery and poor recovery groups, and the chi-square test or Fisher's exact test was used if the frequency of any cell in a contingency table was less than 5, as appropriate. A receiver operating characteristic (ROC) curve analysis was performed to determine the optimal cutoff point of a risk factor that was found to be statistically significant in the univariate analysis. Logistic regression analysis was performed to examine the association of the optimal cutoff point of the risk factor with poor surgical outcome. All $\mathrm{p}$ values are 2 -sided, and $\mathrm{p}$ values $<0.05$ were considered to indicate statistical significance. SPSS software (version 17.0, SPSS Inc.) was used to perform statistical analyses.

\section{Results}

A total of 45 consecutive patients (33 males and 12 females) met the inclusion criteria, with a mean follow-up of $4 \pm 1.6$ years (range $2-6.8$ years). An additional 10 patients had been excluded due to different types of surgeries (anterior decompression in 1 case and posterior decompression and fusion in 9 cases). The patient characteristics are shown in Table 1 . The mean age at the time of surgery was $66.9 \pm 8.6$ years (range $50-85$ years). The average number of expanded laminae was 5.2 (range 3-7). The types of OPLL and number of patients for each were continu- 
K. Maruo et al.
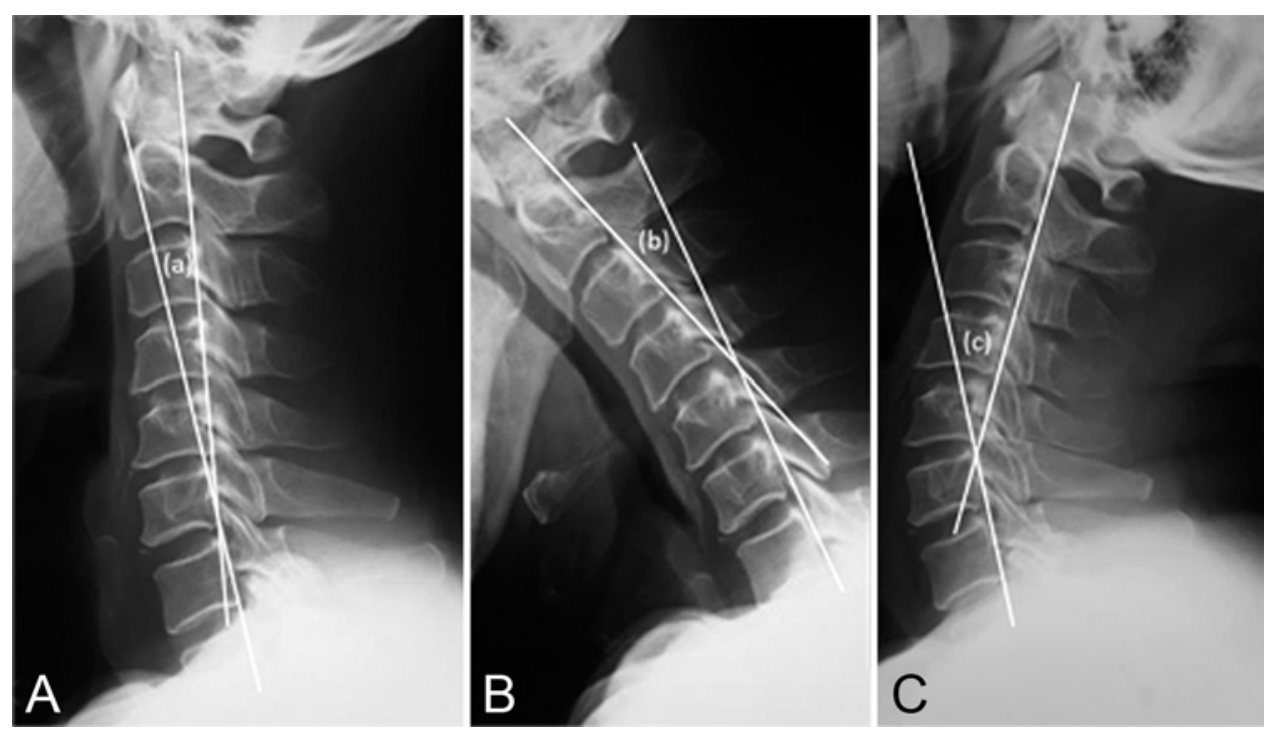

FIG. 1. Measurement of the C2-7 angle. A: Lateral radiograph showing the measurement of the C2-7 lordotic angle. The C2-7 angle was measured between the posterior border of the C-2 vertebral body and the posterior border of the C-7 vertebral body. B and C: The C2-7 ROM was measured by subtracting the maximal extension angle (B) from the maximal flexion angle (C).

ous type in 5 patients (11\%), segmental type in 9 patients (20\%), mixed type in $28(62 \%)$, and unclassified type in 3 patients (7\%). Eight patients had diabetes mellitus. Three patients $(7 \%)$ were classified as K-line (-) (that is, patients whose OPLL crossed the K-line, a straight line connecting the midpoints of C-2 and C-7, as described by Fujiyoshi et al. ${ }^{7}$ ). The mean JOA score significantly increased from 9.1 \pm 2.6 to $13.3 \pm 2.0(\mathrm{p}<0.001)$ at the 2 -year follow-up and to $13.1 \pm 2.3(\mathrm{p}<0.001)$ at the last follow-up. The mean recovery rate was $51.2 \% \pm 25.8 \%$ (range $4.5 \%-100 \%$ ). Figure 2 illustrates the distribution of recovery rate after laminoplasty. Intraoperative and postoperative complications associated with laminoplasty included axial pain in 5 patients, C-5 palsy in 3 patients, infection in 1 patient, and dural tear in 1 patient. Among 45 patients, 19 patients $(42 \%)$ were classified into the poor clinical outcome group (recovery rate $<50 \%$ ). The mean preoperative JOA scores for the good group and poor group were not significantly different (9.1 vs 9.1, p = 0.991). The postoperative JOA score was significantly improved in the good clinical outcome group relative to that of the poor outcome group at 2 years after surgery (14.2 vs 12.2 , respectively; $p<0.001)$ and at the final follow-up (14.4 vs 11.4, respectively; $\mathrm{p}<$ 0.001 ) (Table 2). In the poor clinical outcome group, there was a trend toward older average patient age relative to that in the good clinical outcome group, although the difference was not significant $(68.1 \pm 8.5$ vs $66.0 \pm 8.7$ years, respectively; $p=0.435$ ). None of the patient factors, including sex, preoperative JOA score, preoperative SSEPs, MEPs, BMI, or diabetes mellitus, were independent predictors of poor clinical outcome (Table 2). The preoperative C2-7 angle was similar in both groups (14.6 $6^{\circ}$ vs $16.1^{\circ}$, $\mathrm{p}=0.582$ ). The postoperative $\mathrm{C} 2-7$ angle was significantly decreased in the good clinical outcome group at final follow-up $\left(10.9^{\circ}, p=0.010\right)$ and slightly decreased in the poor clinical outcome group $\left(14.2^{\circ}, \mathrm{p}=0.228\right)$. However, there
TABLE 1: Patient characteristics*

\begin{tabular}{lc}
\hline \multicolumn{1}{c}{ Variable } & Value \\
\hline no. of patients & 45 \\
age at time of surgery (yrs) & \\
mean \pm SD & $66.9 \pm 8.6$ \\
range & $50-85$ \\
no. of males & $33(73)$ \\
follow-up duration (yrs) & \\
mean \pm SD & $4 \pm 1.6$ \\
range & $2-6.8$ \\
type of OPLL & \\
continuous & $5(11)$ \\
segmental & $9(20)$ \\
mixed & $28(62)$ \\
unclassified & $3(7)$ \\
no. of expanded laminae & \\
3 & $1(2)$ \\
4 & $8(18)$ \\
5 & $23(51)$ \\
6 & $8(18)$ \\
7 & $5(11)$ \\
K-line (-) & $3(7)$ \\
BMI & $25.3 \pm 3.5$ \\
mean \pm SD & $17.3-31.7$ \\
range & $8(18)$ \\
diabetes mellitus & \\
\hline
\end{tabular}

* Values are presented as the number of patients (\%) unless indicated otherwise. 


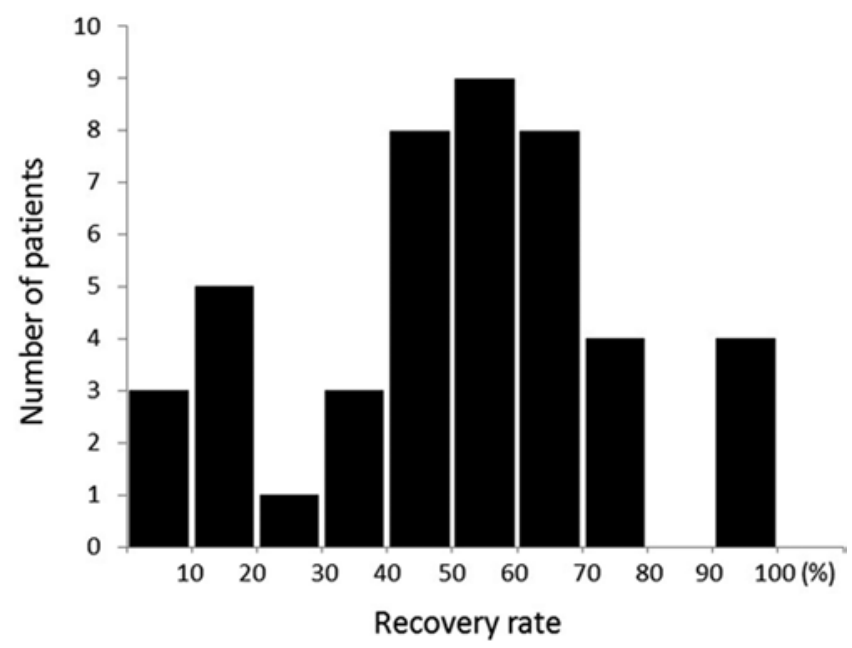

FIG. 2. Bar graph showing the distribution of the recovery rate.

was no significant difference in the postoperative C2-7 angle at the final follow-up. In addition, the change in the C2-7 angle was similar in both groups $\left(-3.7^{\circ}\right.$ vs $-1.9^{\circ}, \mathrm{p}=$ 0.372 ). These results indicate that the loss of cervical lordosis after laminoplasty did not have an impact on the surgical outcome. The occupying ratio of OPLL was similar in both groups $(36.7 \%$ vs $35.7 \%, p=0.796)$. Five patients had an occupying ratio of OPLL of greater than $50 \%$ in this series. A T2 high-intensity lesion on MRI was more likely to be found in the poor clinical outcome group than in the good outcome group (63\% vs $46 \%$, respectively); however, this difference was not significant $(\mathrm{p}=0.259)$. Regarding dynamic factors of the cervical spine, the preoperative C2-7 ROM was significantly greater in the poor clinical outcome group than in the good clinical outcome group $\left(23.1^{\circ}\right.$ vs $\left.14.4^{\circ}, \mathrm{p}=0.009\right)$. On the other hand, the segmental ROM at the responsible level of myelopathy was similar in both groups $\left(5.6^{\circ}\right.$ vs $\left.5.5^{\circ}, \mathrm{p}=0.898\right)$. These results suggested that only the preoperative C2-7 ROM was significantly associated with a poor clinical outcome. The ROC analysis showed that the optimal cutoff point of the preoperative $\mathrm{C} 2-7 \mathrm{ROM}$ was $20^{\circ}$, which maximized the sum of the sensitivity and specificity (Table 3). The logistic regression analysis revealed that patients with a preoperative C2-7 ROM of greater than $20^{\circ}$ had a 4.583 times higher risk (95\% CI 1.263-16.635, $\mathrm{p}=0.021)$ of a poor clinical outcome.

\section{Discussion}

After laminoplasty, the overall average JOA score improved significantly, and the average recovery rate was $51.2 \%$. No patient had severe complications or late neurological deterioration during the average 4-year follow-up period. Several authors have reported limitations of laminoplasty for OPLL. Iwasaki et al. indicated that the surgical outcome was significantly poorer in patients with an OPLL occupying ratio of greater than $60 \% .{ }^{13}$ Fujiyoshi et al. proposed the K-line as a new index to evaluate both cervical kyphosis and size of the OPLL. ${ }^{7}$ Patients with large OPLLs and kyphotic cervical alignment were excluded in
TABLE 2: Comparison of patient characteristics between good and poor clinical outcome groups*

\begin{tabular}{|c|c|c|c|}
\hline Variable & $\begin{array}{l}\text { Good Outcome } \\
\qquad(n=26)\end{array}$ & $\begin{array}{l}\text { Poor Outcome } \\
\quad(n=19)\end{array}$ & $\mathrm{p}$ Value \\
\hline $\begin{array}{l}\text { mean age at time of sur- } \\
\text { gery (yrs) }\end{array}$ & $66.0 \pm 8.7$ & $68.1 \pm 8.5$ & 0.435 \\
\hline male sex & $21(81)$ & $12(63)$ & 0.259 \\
\hline \multicolumn{4}{|l|}{$\begin{array}{l}\text { mean preop CMCT } \\
\text { (msec) }\end{array}$} \\
\hline MEP & $11.6 \pm 3.4$ & $10.6 \pm 2.8$ & 0.335 \\
\hline SSEP & $6.0 \pm 1.8$ & $6.6 \pm 1.1$ & 0.234 \\
\hline mean preop JOA score & $9.1 \pm 3.0$ & $9.1 \pm 2.1$ & 0.991 \\
\hline $\begin{array}{l}\text { mean JOA score at final } \\
\text { follow-up }\end{array}$ & $14.4 \pm 1.9$ & $11.4 \pm 1.7$ & $<0.001 \dagger$ \\
\hline mean recovery rate $(\%)$ & $68.9 \pm 15.7$ & $27.1 \pm 16.2$ & $<0.001 \dagger$ \\
\hline $\begin{array}{l}\text { mean follow-up duration } \\
\text { (days) }\end{array}$ & $1557.1 \pm 607.6$ & $1303 \pm 570.3$ & 0.163 \\
\hline mean BMI & $25.9 \pm 3.1$ & $24.6 \pm 3.9$ & 0.227 \\
\hline no. w/ diabetes mellitus & $6(23)$ & $2(11)$ & 0.227 \\
\hline $\begin{array}{l}\text { presence of high T2 } \\
\text { signal }\end{array}$ & $12(46)$ & $12(63)$ & 0.259 \\
\hline $\begin{array}{l}\text { mean preop C2-7 angle } \\
\left({ }^{\circ}\right)\end{array}$ & $14.6 \pm 6.5$ & $16.1 \pm 10.3$ & 0.582 \\
\hline $\begin{array}{l}\text { mean preop C2-7 ROM } \\
\left({ }^{\circ}\right)\end{array}$ & $14.4 \pm 10.1$ & $23.1 \pm 11.1$ & $0.009+$ \\
\hline $\begin{array}{l}\text { mean preop segmental } \\
\text { ROM }\left({ }^{\circ}\right)\end{array}$ & $5.6 \pm 4.0$ & $5.5 \pm 3.0$ & 0.898 \\
\hline $\begin{array}{l}\text { mean occupying ratio of } \\
\text { OPLL (\%) }\end{array}$ & $36.7 \pm 12.4$ & $35.7 \pm 14.0$ & 0.796 \\
\hline $\begin{array}{l}\text { mean postop C2-7 angle } \\
\left({ }^{\circ}\right)\end{array}$ & $10.9 \pm 9.0$ & $14.2 \pm 11.8$ & 0.289 \\
\hline $\begin{array}{l}\text { mean change in } \mathrm{C} 2-7 \\
\text { angle }\left(^{\circ}\right)\end{array}$ & $-3.7 \pm 6.8$ & $-1.9 \pm 6.6$ & 0.372 \\
\hline
\end{tabular}

* Values are presented as the number of patients (\%) unless indicated otherwise. Mean values are presented as the mean \pm SD. CMCT = central motor conduction time.

† Statistically significant.

this retrospective case series. Alternatively, cervical laminectomy and instrumented fusion provide stability of the decompressed levels and prevent progressive kyphosis. ${ }^{11,14}$ Posterior decompression and instrumented fusion surgery were also chosen in cases of kyphotic alignment or large OPLL. In fact, there were only 5 patients with an occupying ratio of greater than $50 \%$ and 3 patients were classified as K-line (-). The clinical results of this study indicated that double-door laminoplasty for cervical OPLL was safe and effective.

Even though patients with poor prognoses were excluded, $42 \%$ of the patients in this study had a recovery rate of less than $50 \%$. In the present study, a preoperative C2-7 ROM of greater than $20^{\circ}$ was the only significant independent predictor associated with a poor clinical outcome. Recent reports have described the importance of dynamic factors, such as segmental instability and cervical spine mobility. Masaki et al. indicated that the segmen- 
TABLE 3: Result of ROC analysis to illustrate cutoff points of preoperative $\mathrm{C} 2-7 \mathrm{ROM}$

\begin{tabular}{ccc}
\hline Preop C2-7 ROM (cutoff point) & Sensitivity (\%) & Specificity (\%) \\
\hline $17^{\circ}$ & 73.7 & 53.8 \\
$18^{\circ}$ & 73.7 & 61.5 \\
$19^{\circ}$ & 68.4 & 69.2 \\
$20^{\circ}$ & 68.4 & 73.1 \\
$21^{\circ}$ & 57.9 & 76.9 \\
$22^{\circ}$ & 52.6 & 76.9 \\
\hline
\end{tabular}

tal ROM at the level of maximum cord compression was significantly greater in the poor outcome group than in the good outcome group. ${ }^{16}$ They recommended anterior decompression and fusion for patients who had hypermobile segments. This finding differs from the current study's result in which the segmental ROM at the responsible level was similar in both groups $\left(5.6^{\circ}\right.$ vs $\left.5.5^{\circ}\right)$. Matsunaga et al. reported that the $\mathrm{C} 1-7 \mathrm{ROM}$ was significantly greater in patients with myelopathy than in those without in patients with less than $60 \%$ canal stenosis..$^{18,20}$ Ogawa et al. found that the clinical outcomes of laminoplasty were worse in patients with segmental-type OPLL. A greater C2-7 ROM in segmental-type OPLL was found to have a significant correlation with late deterioration. ${ }^{22}$ These findings may suggest that cervical mobility may have an impact on the clinical outcome after laminoplasty.

Preoperative severity of myelopathy is one of the important predictors associated with good surgical outcomes. MEPs and SSEPs have been reported to be useful parameters for the prediction of surgical outcome..$^{10,24}$ Takahashi et al..$^{24}$ reported that the central motor conduction time significantly correlated with the preoperative JOA score. In the present study, the preoperative JOA score as well as MEPs and SSEPs did not correlate with the clinical outcomes of laminoplasty. High signal intensity on T2-weighted MR images of the spinal cord has previously been shown to be a predictor of poor clinical outcome. In this study, the frequency of T2 high-intensity lesions was not significantly different between the groups. These results indicate that the baseline preoperative severity of myelopathy did not correlate with clinical outcomes.

Preoperative cervical lordosis and loss of cervical lordosis after laminoplasty have been reported to be predictors of poor surgical outcome. ${ }^{16,23}$ In the present series, the pre- and postoperative $\mathrm{C} 2-7$ angles as well as the change in C2-7 angle were not significantly different between the groups. Thus, a dynamic factor was the only significant independent predictor of poor surgical outcome. Anterior decompression and fusion surgery has been reported to be more of an appropriate surgery for cervical OPLL. However, it is technically difficult to remove or float the OPLL through an anterior approach, and reconstruction of the cervical spine after multilevel corpectomy is complicated. Alternatively, posterior decompression with instrumented fusion surgery provided a good surgical outcome in $71.1 \%$ of patients with an average 4.8-year follow-up. ${ }^{4}$ However, a high incidence of postoperative nerve root palsy occurred in 10 of the 83 patients $(12 \%)$. It was concluded that postoperative nerve root palsy was associated with increased cervical lordosis. The indication for posterior decompression with instrumented fusion for patients with OPLL is controversial. Instrumented fusion surgery can prevent progression of kyphosis or OPLL. Therefore, posterior decompression with instrumented fusion without correction of cervical lordosis may be a useful strategy in patients with cervical hypermobility.

A weakness of this study was the relatively small sample size and retrospective data collection. In addition, the postoperative follow-up period may not have been long enough to assess potential neurological deterioration. Evaluation of OPLL type as a risk factor for clinical outcome of laminoplasty was also attempted. Another limitation was the small number of each type of OPLL. A prospective randomized study with a larger sample size and a longer follow-up period is required to compare the influence of the dynamic factors on the clinical outcome after laminoplasty.

\section{Conclusions}

The clinical results showed that double-door laminoplasty for cervical OPLL is safe and effective. Greater preoperative C2-7 ROM was associated with poor clinical outcomes after laminoplasty. This result may suggest that cervical mobility may have an impact on the clinical outcome of laminoplasty. Instrumented fusion surgery may be a useful strategy in patients with cervical hypermobility.

\section{Disclosure}

The authors report no conflict of interest concerning the materials or methods used in this study or the findings specified in this paper.

Author contributions to the study and manuscript preparation include the following. Conception and design: Maruo. Acquisition of data: Maruo. Analysis and interpretation of data: Maruo, Daimon. Drafting the article: Maruo. Critically revising the article: Maruo. Reviewed submitted version of manuscript: all authors. Approved the final version of the manuscript on behalf of all authors: Maruo. Statistical analysis: Maruo, Daimon.

\section{References}

1. Azuma Y, Kato Y, Taguchi T: Etiology of cervical myelopathy induced by ossification of the posterior longitudinal ligament: determining the responsible level of OPLL myelopathy by correlating static compression and dynamic factors. J Spinal Disord Tech 23:166-169, 2010

2. Cardoso MJ, Koski TR, Ganju A, Liu JC: Approach-related complications after decompression for cervical ossification of the posterior longitudinal ligament. Neurosurg Focus 30(3): E12, 2011

3. Chang H, Song KJ, Kim HY, Choi BW: Factors related to the development of myelopathy in patients with cervical ossification of the posterior longitudinal ligament. J Bone Joint Surg Br 94:946-949, 2012

4. Chen Y, Guo Y, Chen D, Wang X, Lu X, Yuan W: Long-term outcome of laminectomy and instrumented fusion for cervical ossification of the posterior longitudinal ligament. Int Orthop 33:1075-1080, 2009

5. Chiba K, Ogawa Y, Ishii K, Takaishi H, Nakamura M, Maruiwa 


\section{Surgical outcome after laminoplasty for cervical OPLL}

$\mathrm{H}$, et al: Long-term results of expansive open-door laminoplasty for cervical myelopathy-average 14-year follow-up study. Spine (Phila Pa 1976) 31:2998-3005, 2006

6. Fujimura Y, Nishi Y, Chiba K, Nakamura M, Hirabayashi $\mathrm{K}$ : Multiple regression analysis of the factors influencing the results of expansive open-door laminoplasty for cervical myelopathy due to ossification of the posterior longitudinal ligament. Arch Orthop Trauma Surg 117:471-474, 1998

7. Fujiyoshi T, Yamazaki M, Kawabe J, Endo T, Furuya T, Koda $\mathrm{M}$, et al: A new concept for making decisions regarding the surgical approach for cervical ossification of the posterior longitudinal ligament: the K-line. Spine (Phila Pa 1976) 33: E990-E993, 2008

8. Fujiyoshi T, Yamazaki M, Okawa A, Kawabe J, Hayashi K, Endo T, et al: Static versus dynamic factors for the development of myelopathy in patients with cervical ossification of the posterior longitudinal ligament. J Clin Neurosci 17:320-324, 2010

9. Hirabayashi K, Miyakawa J, Satomi K, Maruyama T, Wakano $\mathrm{K}$ : Operative results and postoperative progression of ossification among patients with ossification of cervical posterior longitudinal ligament. Spine (Phila Pa 1976) 6:354-364, 1981

10. Holly LT, Matz PG, Anderson PA, Groff MW, Heary RF, Kaiser MG, et al: Clinical prognostic indicators of surgical outcome in cervical spondylotic myelopathy. J Neurosurg Spine 11:112-118, 2009

11. Houten JK, Cooper PR: Laminectomy and posterior cervical plating for multilevel cervical spondylotic myelopathy and ossification of the posterior longitudinal ligament: effects on cervical alignment, spinal cord compression, and neurological outcome. Neurosurgery 52:1081-1088, 2003

12. Iwasaki M, Okuda S, Miyauchi A, Sakaura H, Mukai Y, Yonenobu K, et al: Surgical strategy for cervical myelopathy due to ossification of the posterior longitudinal ligament. Part 1: Clinical results and limitations of laminoplasty. Spine (Phila Pa 1976) 32:647-653, 2007

13. Iwasaki M, Okuda S, Miyauchi A, Sakaura H, Mukai Y, Yonenobu K, et al: Surgical strategy for cervical myelopathy due to ossification of the posterior longitudinal ligament. Part 2: Advantages of anterior decompression and fusion over laminoplasty. Spine (Phila Pa 1976) 32:654-660, 2007

14. Lee SE, Chung CK, Jahng TA, Kim HJ: Long-term outcome of laminectomy for cervical ossification of the posterior longitudinal ligament. Clinical article. J Neurosurg Spine 18:465471,2013

15. Li H, Jiang LS, Dai LY: A review of prognostic factors for surgical outcome of ossification of the posterior longitudinal ligament of cervical spine. Eur Spine J 17:1277-1288, 2008

16. Masaki Y, Yamazaki M, Okawa A, Aramomi M, Hashimoto M, Koda M, et al: An analysis of factors causing poor surgical outcome in patients with cervical myelopathy due to ossification of the posterior longitudinal ligament: anterior decompression with spinal fusion versus laminoplasty. J Spinal Disord Tech 20:7-13, 2007

17. Matsumoto M, Chiba K, Toyama Y: Surgical treatment of os- sification of the posterior longitudinal ligament and its outcomes: posterior surgery by laminoplasty. Spine (Phila Pa 1976) 37:E303-E308, 2012

18. Matsunaga S, Nakamura K, Seichi A, Yokoyama T, Toh S, Ichimura S, et al: Radiographic predictors for the development of myelopathy in patients with ossification of the posterior longitudinal ligament: a multicenter cohort study. Spine (Phila Pa 1976) 33:2648-2650, 2008

19. Matsunaga S, Sakou T: Ossification of the posterior longitudinal ligament of the cervical spine: etiology and natural history. Spine (Phila Pa 1976) 37:E309-E314, 2012

20. Matsunaga S, Sakou T, Taketomi E, Komiya S: Clinical course of patients with ossification of the posterior longitudinal ligament: a minimum 10-year cohort study. J Neurosurg 100 (3 Suppl Spine):245-248, 2004

21. Matsunaga S, Yamaguchi M, Hayashi K, Sakou T: Genetic analysis of ossification of the posterior longitudinal ligament. Spine (Phila Pa 1976) 24:937-939, 1999

22. Ogawa Y, Chiba K, Matsumoto M, Nakamura M, Takaishi H, Hirabayashi $\mathrm{H}$, et al: Long-term results after expansive opendoor laminoplasty for the segmental-type of ossification of the posterior longitudinal ligament of the cervical spine: a comparison with nonsegmental-type lesions. J Neurosurg Spine 3:198-204, 2005

23. Sakai K, Okawa A, Takahashi M, Arai Y, Kawabata S, Enomoto M, et al: Five-year follow-up evaluation of surgical treatment for cervical myelopathy caused by ossification of the posterior longitudinal ligament: a prospective comparative study of anterior decompression and fusion with floating method versus laminoplasty. Spine (Phila Pa 1976) 37:367-376, 2012

24. Takahashi J, Hirabayashi H, Hashidate H, Ogihara N, Yamazaki I, Kamimura M, et al: Assessment of cervical myelopathy using transcranial magnetic stimulation and prediction of prognosis after laminoplasty. Spine (Phila Pa 1976) 33:E15E20, 2008

25. Tani T, Ushida T, Ishida K, Iai H, Noguchi T, Yamamoto H: Relative safety of anterior microsurgical decompression versus laminoplasty for cervical myelopathy with a massive ossified posterior longitudinal ligament. Spine (Phila Pa 1976) 27: 2491-2498, 2002

26. Yoshida M, Otani K, Shibasaki K, Ueda S: Expansive laminoplasty with reattachment of spinous process and extensor musculature for cervical myelopathy. Spine (Phila Pa 1976) 17:491-497, 1992

Manuscript submitted January 5, 2014.

Accepted August 22, 2014.

Please include this information when citing this paper: published online October 3, 2014; DOI: 10.3171/2014.8.SPINE131197.

Address correspondence to: Keishi Maruo, M.D., Department of Orthopaedic Surgery, Department of Biostatistics, Hyogo College of Medicine, Mukogawa-cho 1-1, Nishinomiya, Hyogo 663-8501, Japan.email: kmaruo@hyo-med.ac.jp. 